\title{
PERENCANAAN INTERIOR GRIYA SPA DAN KESEHATAN UNTUK IBU HAMIL DI BLITAR
}

\author{
Galang Sukmana, Putri Sekar Hapsari \\ Program Studi S1 Desain Interior, FSRD \\ Institut Seni Indonesia Surakarta \\ email: putrisekarhapsari@yahoo.com
}

\begin{abstract}
In general, spa spa planning and health for pregnant women in Blitar can generally be interpreted as planning activities of the inner space of a building that is the center of the whole body care activities aimed at mothers who are pregnant (pregnant). In addition to being used as a body treatment for spa, the spa is also expected to be able to interact or exchange experiences about pregnancy between pregnant women with one another or also between pregnant women and therapists on duty. Therefore the need for a body treatment such as a spa. In this work using several approaches, the approach includes the ergonomic approach to know the human dimension and everything related to the five human senses, and the theme or style approach that supports identity / coorporyte identity. This work takes the Mediterranean style with the concept of the park. This style and concept is applied to furniture and interior elements in the form of floors, walls, ceilings.
\end{abstract}

Keywords: Spa interior, Mediterranean style, garden concept.

\section{PENDAHULUAN}

Kota Blitar merupakan salah satu daerah di Propinsi Jawa Timur yang secara geografis Kabupaten Blitar terletak pada $11125^{\prime}-112$ 20' BT dan 7 57-8 9'51 LS berada di Barat Daya Ibu Kota Propinsi Jawa Timur - Surabaya dengan jarak kurang lebih 160 Km. Penduduk merupakan salah satu potensi bagi Kabupaten Blitar untuk menggerakkan pembangunan, namun sebaliknya menjadi permasalahan apabila kualitas sumberdaya manusianya masih rendah. Jumlah penduduk yang besar dengan kualitas SDM yang tinggi akan sangat mendukung pemerintah dalam mencapai tujuan-tujuan kesejahteraan masyarakat.

Adapun jumlah penduduk Kabupaten Blitar pada tahun 2013 mencapai 1.268.194 jiwa, terdiri dari penduduk perempuan 637.419 jiwa dan laki - laki 630.7754 jiwa. Adapun tingkat pertumbuhan penduduk Kabupaten Blitar mencapai 0,80\%. Saat ini gaya hidup masyarakat semakin berkembang dan maju seiring perkembangan jaman. Banyak pengaruh dari luar kota Blitar yang masuk mempengaruhi gaya hidup masyarakat Blitar. Salah satu gaya hidup masyarakat Blitar saat ini adalah tentang perawatan dan kecantikan yang diperuntukkan untuk para kaum wanita. 
Ibu hamil sangat diperhatikan kesehatannya, jika ibu yang sedang hamil melakukan pekerjaan yang terlalu berat dan sampai membuat ketahanan fisik menurun dan pikiran menjadi stres tentunya akan berdampak juga pada kandungannya. Dari dampak itulah, kini banyak dikembangkan pusat-pusat pelayanan publik yang lebih mengarah kepada entertainment atau hiburan, salah satu dari pelayanan publik itu adalah SPA dan bahkan telah menjadi trend dimana-mana mengingat pentingnya merelaksasikan tubuh bagi setiap kegiatan.

Kata SPA berasal dari masa Kekaisaran Romawi. Pada masa itu terjadi pertempuran hebat. Kemudian, dicari suatu cara untuk memulihkan pasukan militernya dari luka-luka dan penyakit. Dari usaha tersebut dirancang tempat mandi atau tempat berendam disekitar sumur-sumur air panas untuk menyembuhkan badan mereka yang sakit. Tempat ini disebut "aquae" dan perawatan mandinta disebut "Sanus Saban Aquam" yang artinya kesehatan oleh/melalui air atau "Sanitas per Aqua" (SPA).

Spa (Sanitas Per Aquam) merupakan suatu fasilitas pusat pemulihan kesehatan fisik maupun spiritual (Rejuvenation Center) dengan aktivitas relaksasi dan penyegaran seperti health screening, wellness center dan SPA and beauty center yang dikemas dengan pendekatan-pendekatan alamiah yang mengombinasikan pemanfaatan teknologi tinggi dan teknik-teknik tradisional.

Hampir setiap wanita menyukai memanjakan diri di tempat spa karena mereka dapat memperoleh perawatan tubuh dengan menggunakan bahan-bahan alami yang ditawarkan. Perencanaan interior spa ini diperuntukkan bagi para wanita yang sedang mengandung (hamil) yang ingin meremajakan kulit dan merileksasikan tubuh mereka dengan nyaman. Fasilitas yang akan dibuat meliputi lobby, Ruang perawatan tubuh, Ruang perawatan kaki dan tangan, Ruang perawatan rambut, area kolam renang, area yoga dan senam, dan tempat bilas. Tema perencanaannya adalah taman yang diharapkan bisa menciptakan suasana yang segar, rileks, nyaman, tenang, sesuai dengan kebutuhan pelanggan..

Perkembangan spa yang sangat meningkat dratis, di kota-kota besar seperti Jakarta, Surabaya, Bandung, Bali banyak kita jumpai. Di kota-kota tersebut banyak sekali tempat-tempat spa yang dikhususkan hanya untuk perempuan, laki-laki, anak-anak sampai ibu hamil dan setelah melahirkan. Di kota Blitar sendiri juga banyak tempat-tempat spa yang dikhususkan hanya untuk perempuan, laki-laki dan anak-anak saja atau dengan kata lain tidak adanya tempat spa yang dikhususkan untuk para ibu yang sedang mengandung (hamil).

Pemilihan kota untuk perencanaan interior Griya Spa dan kesehatan untuk ibu hamil ini difokuskan di daerah kota Blitar. Pemilihan tempat ini dirasa cocok karena Blitar kota menjadi pusat berkumpulnya masyarakat Blitar secara keseluruhan dalam bidang pekerjaan, hiburan, kuliner, wisata dan suatu wilayah yang banyak ditinggali oleh masyarakat kota Blitar dengan penghasilan menengah keatas. Selain itu pemilihan lokasi ini dikarenakan di daerah Blitar kota yang menjadi pusat masyarakat.

Untuk itu demi memfasilitasi ketiadakan tempat Spa yang dikhususkan untuk ibu hamil maka penulis memutuskan untuk membuat perencanaan Griya spa untuk ibu hamil di kota Blitar. Selain itu penulis memilih tema taman sebagai perencanaan interior untuk tugas akhir dengan judul perencanaan interior Griya Spa dan kesehatan untuk ibu hamil di kota blitar. Dengan mengadopsi tema tersebut diharapkan spa ini bisa menjadi tempat yang berguna 
bagi para ibu hamil dengan tingkat kesibukan yang berat untuk meluangkan waktu untuk berolahraga ringan dan memanjakkan tubuh mereka tanpa harus menyita banyak waktu dan fisik para ibu-ibu hamil di kota Blitar maupun sekitar kota Blitar.

\section{A. Pendekatan Pemecahan Desain}

Pendekatan pemecahan desain merupakan seperangkat teori yang dirumuskan berdasarkan landasan teori dan kreatifitas untuk memcahkan desain/ menemukan desain yang tepat. Peran desainer sangatlah penting agar dapat menyampaikan karakter dalam perwujudan desain interior yang mampu menciptakan dan menyampaikan cirri khas pada sebuah desain. Untuk menyelesaikan permasalahan tersebut dapat menggunakan beberapa pendekatan sebagai acuan pendekatan pemecahan desain, diantaranya pendekatan Fungsi, Estetika, dan Ergonomi yaitu :

\section{Pendekatan Tema}

Perencanaan Interior Griya Spa dan Kesehatan untuk Ibu Hamil di Blitar ini menggunakan tema taman. Taman dapat memberikan inspirasi yang sangat beragam bagi pemiliknya, dengan taman orang akan merasakan kenyamanan, keindahan serta kesejukan baik batin maupun fisik. Sering kita terpesona atau kagum dengan keindahan taman, merasakan keindahan hasil sentuhan manusia dalam menata seta membentuk ruang menjadikannya magnet yang dapat dinikmati serta dijadikan sebagai tempat yang memiliki sudut pandang favorit bagi penghuni maupun pengunjung atau tamu yang datang.

Taman merupakan hasil karya cipta manusia yang terdiri dari perpaduan antara unsur-unsur alami maupun buatan sehingga membentuk suatu kesatuan desain yang memberikan keindahan, keasrian serta mengandung nilai seni yang dapat dinikmati secara langsung. Unsurunsur pendukung taman yang terdiri dari unsur lunak atau disebut juga Softscape serta unsur keras atau disebut Hardscape, baik itu alami maupun buatan. Unsur lunak yang dimaksud seperti tanaman mulai dari jenis rumput, penutup tanah (Ground cover), semak, perdu sampai dengan jenis pohon. Sedangkan unsure keras merupakan unsure taman yang merupakan benda mati yang dijadikan sebagai pendukung terbentuknya taman sebagai contoh : kendi, patung, lampu taman, keramik batu-batuan atau unsur-unsur lain yang merupakan buatan manusia yang dibuat melalui proses fabrikasi sementara bahannya sendiri merupakan bahan alami yang terdapat di alam.

Berdasarkan referensi yang dijelaskan diatas maka dalam perencanaan ini tema taman menjadi fokus garap. Untuk mendukung tema taman maka digunakanlah unsur-unsur taman Softscape (unsur lunak) dan Hardscape (unsur keras) yang diaplikasikan pada masing-masing ruang. Dengan perencanaan interior yang ditujukan kepada para kaum ibu-ibu yang sedang hamil diharapkan tema taman ini sesuai.

\section{Pendekatan Fungsi}

Secara umum tolak ukur perencanaan desain interior adalah menciptakaan sarana berupa interior/ ruang dalam untuk manusia. Untuk kepentingan itu dari sisi manusia sebagai pengguna desain maka ada tiga unsur yang harus diperhatikan, yaitu : aktivitas, kapasitas, dan ergonomic calon pengguna. Ruang merupakan sarana aktivitas manusia didalamnya, ada unsur yang harus diperhatikan, yakni : fungsi dan dimensi. Merujuk pada uraian itu maka interior sebagai sarana harus memenuhi persyaratan: teknis dan estetis sebagai bagian untuk merumuskan norma desain. Desain yang baik adalah desain yang dapat memenuhi kebutuhan fungsi. Seiring dengan perkembangan perdaban 
manusia, fungsi interior memiliki sejuta makna yang harus dapat ditangkap yang selanjutnya dapat diterjemahkan oleh seorang desainer.

Griya spa dan kesehatan ini tidak hanya tempat untuk merawat tubuh ibu hamil, tetapi juga dapat digunakan para ibu hamil untuk sharing. Sebagai sarana publik Griya Spa dan kesehatan ibu hamil memberikan fasilitas yang sangat mendukung. Berdasarkan dari kegiatan yang dilakukan maka terdapat beberapa ruang-ruang yang sesuai dengan kegiatan tersebut. Ruang-ruang yang digunakan dalam perencanaa ini memiliki tiga sifat diantaranya yaitu publik, semi public, dan privat. Akan tetapi yang menjadi batasan perencanaan ruang diantaranya :

a. Lobby, merupakan ruang pertama yang dituju oleh pengunjung. di Lobby pengunjung bisa melakukan pendaftaran, mendapatkan informasi dan menunggu didalam Lobby ini terdapat ruang informasi, ruang pendaftaran, ruang tunggu dan Lavatory

b. Ruang perawatan tubuh, merupakan ruangan yang ditujukan untuk merawat seluruh tubuh seperti body massages, body treatments dan facial.

c. Ruang perawatan kaki dan tangan, merupakan ruangan yang ditujukan untuk merawat pada bagian tangan dan kaki seperti manicure dan pedicure.

d. Ruang perawatan rambut, merupakan ruangan yang ditujukan untuk merawat rambut seperti haircut dan hairwash.

e. Area senam dan yoga, merupan area yang cukup luas untuk melakukan kegiatan senam hamil dan meditasi (yoga).

f. Ruang bilas, merupakan fasilitas yang harus ada di setiap tempat spa untuk membilas tubuh setelah melakukan perawatan.

\section{Pendekatan Estetika}

Dalam teori estetika mempelajari berbagai macam elemen yang terkandung dalam seni bentuk, seperti titik, garis, bidang, bentuk, ruang, proporsi, harmoni, tekstur, psikologi, dan lain sebaginya. Dalam proses perancangan, seorang desainer harus mampu melihat fenomena-fenomena yang berada disekitarnya secara realitas mengenai kebutuhan-kebutuhan manusia dan mencoba memberikan solusi pada keadaan disekelilingnya. Solusi tersebut dapat diterjemahkan ke dalam bentuk - bentuk yang dapat memenuhi kebutuhan orang lain secara fisik dan psikologis yang mengandung nilainilai keindahan dan kegunaan.

Untuk mewujudkan desain yang mampu memenuhi kebutuhan faktor kesenangan bagi penghuni atau untuk menunjukkan identitas perlu adanya pendekatan bentuk untuk mendukung estetis. Pendekatan yang tujuannya untuk mendukung identitas/ coorporyte identity atau untuk mendukung factor kesenangan erat dengan kaitannya dengan tema atau gaya interior. Gaya atau tema interior dapat dihadirkan dengan mengolah unsur pembentuk ruang, furniture, tata letak ruang serta kehadiran konstruksi elemen interior.

Pada pendekatan pemecahan desain yang berkaitan dengan pendekatan tema, maka desainer dapat menggunakan pendekatan yang berkaitan dengan identitas sebuah wadah untuk penciptaan suasana. Penciptaan suasana interior penting diwujudkan dengan harapan orang akan menangkap pesan rasa dari interior dan akhirnya orang akan selalu ingat dan ingin kembali hadir menikmati suasana tersebut. 


\section{Pendekatan Ergonomi}

Ergonomi mempunyai arti penting dalam perancangan desain interior, oleh karena dengan memperhatikan faktor-faktor ergonomic para pemakai ruang akan mendapatkan produktifitas dan effisiensi kerja yang berarti suatu penghematan dalam penggunaan ruang (space). Ergonomi adalah suatu ilmu yang mempelajari tentang kondisi fisik seseorang dalam melakukan kerja. Pengertian ergonomi sangat luas tidak hanya terbatas pada sisi-sisi fisik saja tetapi juga meliputi segala hal yang bersangkutan dengan ke lima indera manusia. Ergonomi pada tiap-tiap ruang pada Griya Spa dan Kesehatan untuk Ibu Hamil ini akan berbeda sesuai dengan fungsi dan aktivitas didalamnya. Perbedaan aktivitas pada tiap-tiap ruang ini akan memiliki ukuran dan dimensi yang berbeda yang akan mempengaruhi bentuk furniture dan kenyamanan pengguna.

\section{B. Ide Perancangan}

Gaya arsitektur Mediterania adalah suatu gaya utuh dengan unsur-unsur pembentuk yang berdesain tertentu. Ketika kita mendengar gaya arsitektur mediterania, maka bayangan tentang bangunannya mungkin akan sama, yaitu bangunan dengan gaya berciri khas lengkung, dan berpilar.

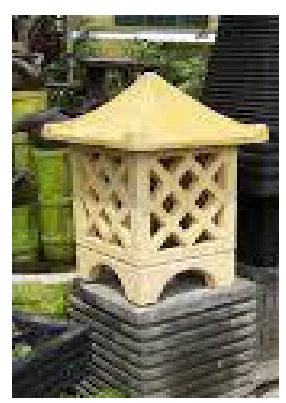

(Sumber : www.agrotamasumatra.blogspot.com)

Dengan diperlihatkan unsur-unsur kolom, aksen lengkung pada jendela maupun dinding, dan list profil pada ceiling. Pemilihan warna putih serta penggunaan lantai terakota akan mempertegas gaya mediterania.

\section{PEMBAHASAN}

Berdasarkan uraian arti kata per kata dari judul ini, maka yang dimaksud dengan perencanaan Interior Griya Spa dan Kesehatan untuk Ibu Hamil di Blitar ialah Suatu bangunan arsitektur yang mempunyai ruang dalam yang bertujuan untuk merawat dan membantu menjaga kesehatan tubuh ibu yang sedang mengandung.

\section{Site plan}

Site plan Spa dan kesehatan untuk ibu hamil di Blitar dipilih di pusat kota dan di area wisata makam bung Karno sebagai salah satu destinasi Kota Blitar tepatnya di jalan Dr. Wahidin Kota Blitar. Lokasi tersebut merupakan lahan kosong dengan keluasan sekitar $2000 \mathrm{~m}^{2}$.

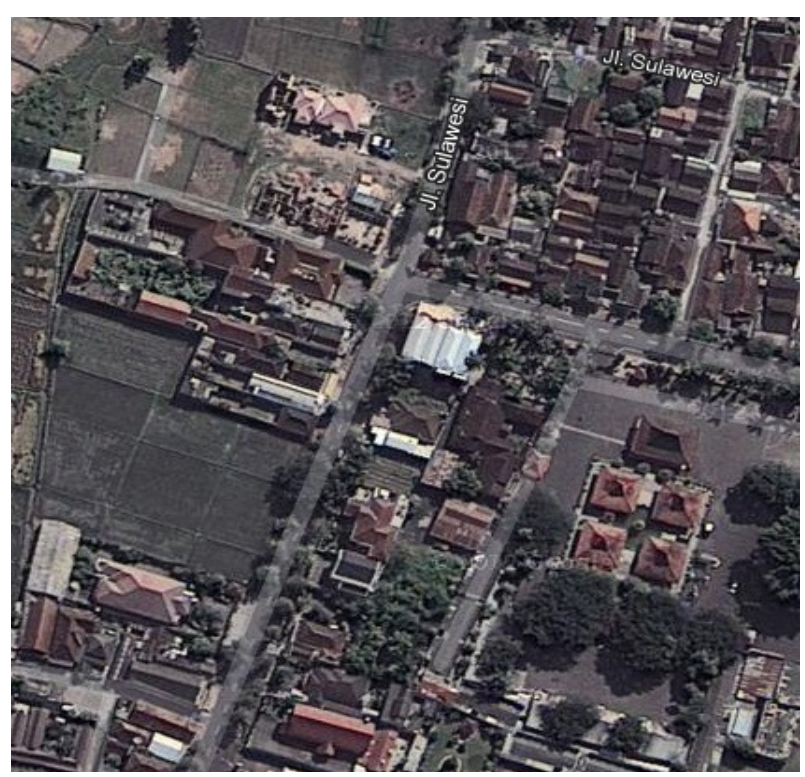

Gambar 9 Sumber : www.google.com 


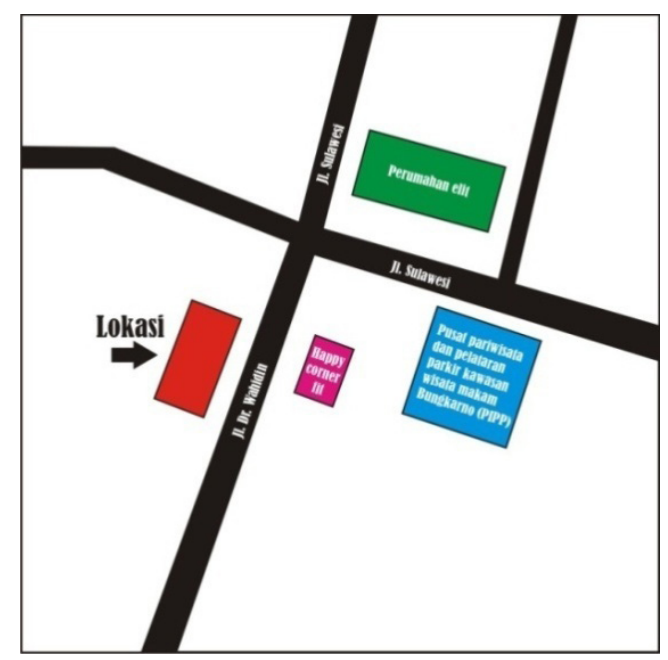

Gambar 10

Sumber : Galang, 10 Juli 2014

\section{Struktur Organisasi}

Griya spa dan kesehatan untuk ibu hamil ini mempunyai struktur organisasi yang dibedakan dari masing-masing tugas. Jabatan paling atas terdapat manager yang bertugas memimpin perusahaan dan menjadi penanggung jawab kebijakan-kebijakan yang telah ditetapkan perusahaan. Satu tingkat dibawah manager terdapat operasional manager yang bertugas untuk mengelola dan mengkordinasikan tugas-tugas pada kelompok kerja spa. Operasional manager dibantu oleh beberapa staf diantaranya ada accounting yang bertugas untuk mengatur dan mengelola anggaran perusahaan. Receptionist bertugas sebagai penerima tamu baik tamu perusahaan maupun konsumen. Terapis, dalam struktur ini terapis dibedakan menjadi dua yaitu, terapis spa dan kesehatan untuk terapis spa dibedakan menjadi tiga diantaranya terapis bagian tangan, terapis bagian rambut (salon), terapis bagian badan. Sedangkan untuk terapis kesehatan juga dibedakan menjadi tiga diantanranya terapis bagian senam (instruktur senam), terapis bagian yoga (instruktur yoga) dan terapis bagian renang (instruktur renang). Semuanya mempunyai tugas sesuai dengan keahliannya. Agar griya spa ini tetap terjaga kebersihannya maka diberi petugas bersih-bersih (cleaning service).

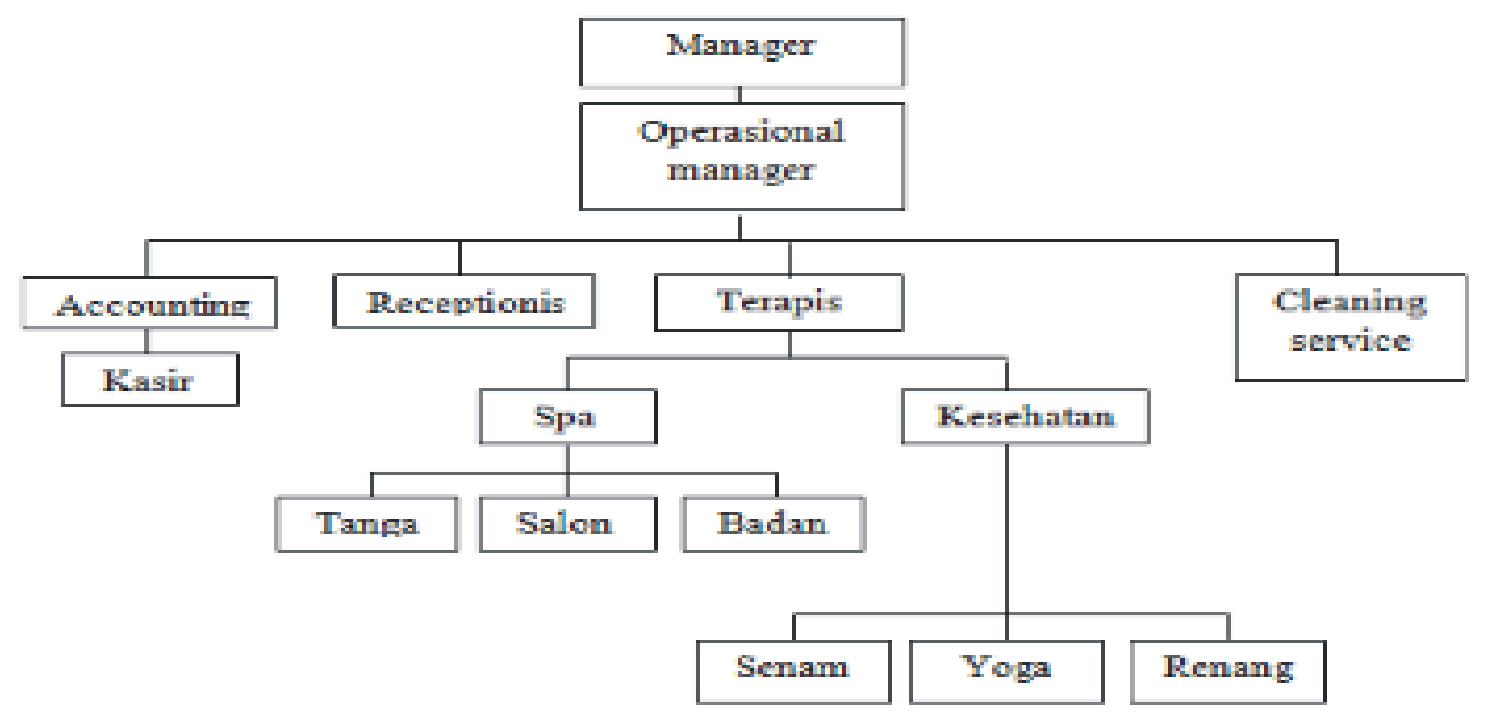

Skema 2. Struktur organisasi 


\section{Hasil dan pembahasan desain}

\section{a. Ruang lobby}

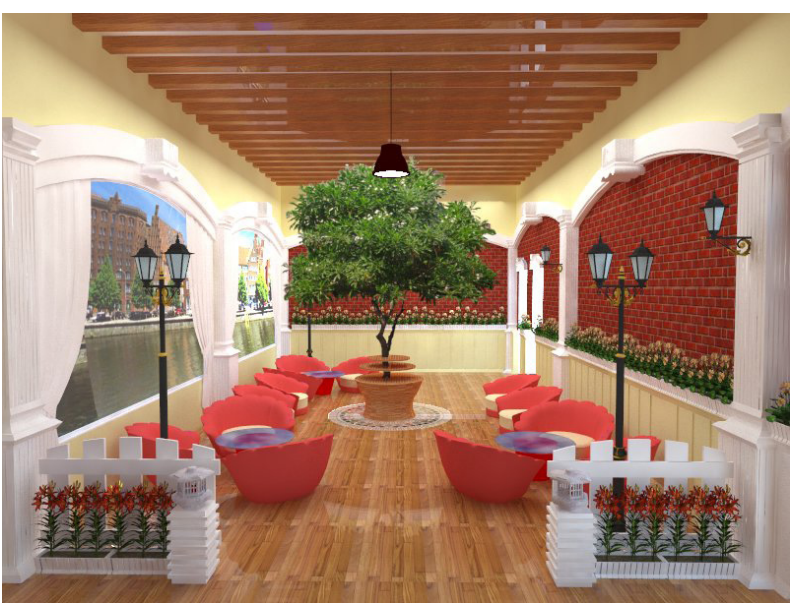

Gambar 11

Sumber : Galang, 15 November 2014

\begin{tabular}{|c|c|c|}
\hline $\begin{array}{l}\text { N a m a } \\
\text { Ruang }\end{array}$ & Kelebihan & Kekurangan \\
\hline$\angle O B B Y$ & $\begin{array}{l}\text { 1. Ruangan luas } \\
\text { 2. Penghawaan bagus } \\
\text { 3. Pencahayaan men- } \\
\text { dukung suasana }\end{array}$ & $\begin{array}{l}\text { Dinding motif } \\
\text { susah dibersihkan }\end{array}$ \\
\hline
\end{tabular}

Pada ruangan lobby ditampilkan penggabungan antara konsep taman dengan gaya Mediterania yang telah ditetapkan. Konsep taman pada lobby bagian ruang tunggu terlihat pada pohon sintetis yang diletakkan ditengah tengah kelompok sofa dengan pot yang menopang pohon tersebut difungsikan sebagai tempat majalah/ buku. Hal ini dimaksudkan supaya pengunjung bisa membaca majalah sembari menunggu giliran perawatan. Tambahan lampu taman, pagar taman, dan barisan-barisan tanaman juga termasuk dari unsur taman yang diambil. Aksen aksen lengkung pada pilar dinding merupakan unsure dari gaya mediterania.

\section{b. Ruang perawatan tubuh}

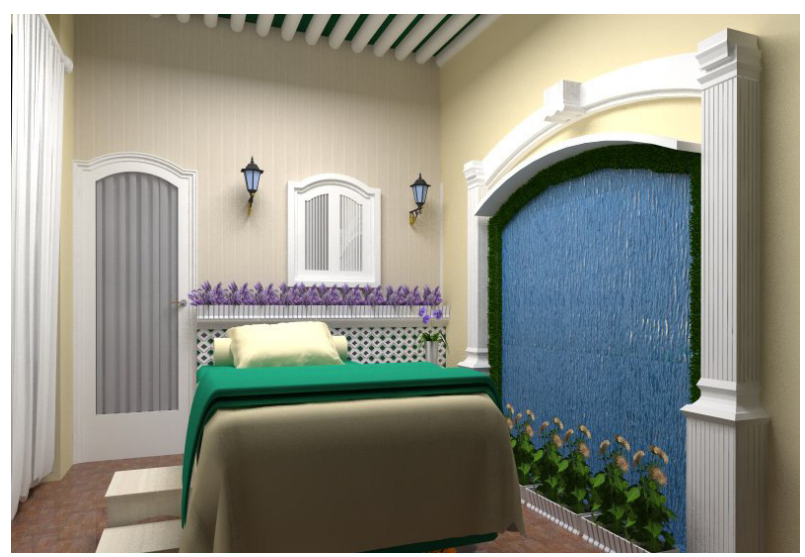

Gambar 12

Sumber : Galang, 15 November 2014

\begin{tabular}{|l|l|l|}
\hline \multicolumn{1}{|c|}{$\begin{array}{c}\text { Nama } \\
\text { Ruang }\end{array}$} & \multicolumn{1}{|c|}{ Kelebihan } & Kekurangan \\
\hline RUANG & 1. Ruang berbentuk segi & Ruangan \\
PER- & empat sehingga sirkulasi & kurang luas \\
AWATAN & Udara & \\
TUBUH & $\begin{array}{l}\text { 2. Suara gemercik air dari } \\
\text { water wall menghidupkan } \\
\text { suasan alam }\end{array}$ & \\
\hline
\end{tabular}

Ruang perawatan tubuh pada Griya $S p a$ ini mempunyai tiga ruangan perawatan yang masing-masing ruang diberi pembatas dari waterwall dengan tambahan barisan tanaman dibagian bawah dan rumput sintetis dibagian atas, kanan dan kiri air. Hal ini selain untuk menampilkan kesan taman alami juga berfungsi sebagai pembatas transparan antara ruang satu dengan ruangan lainnya dan ini merupakan aturan standart dari peraturan yang telah ditulis oleh Asosiasi Spa Indonesia (ASPI) yang bekerja sama dengan Dinas pariwisata provinsi Daerah Istimewa Yogyakarta, disebutkan bahwa ruangan pada tempat spa tidak boleh tertutup rapat supaya menghindari adanya perbuatan pelecehan. Jika dilihat pada gambar diatas disamping tempat tidur terdapat undakan. Undakan tersebut berfungsi sebagai pijakan untuk membantu pasien naik dan meletakkan tubuhnya di tempat tidur. 


\section{c. Ruang perawatan kaki dan tangan}

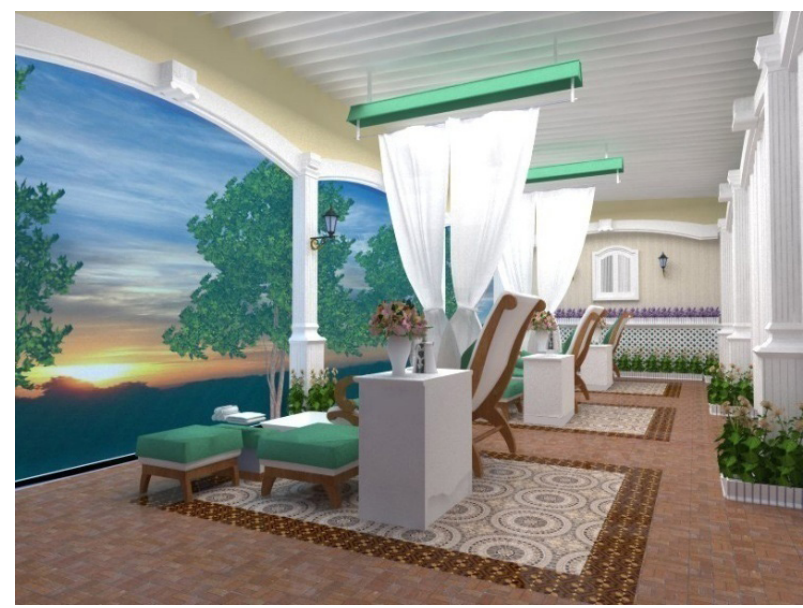

Gambar 13

Sumber : Galang, 15 November 2014

\begin{tabular}{|c|c|c|}
\hline Nama Ruang & Kelebihan & Kekurangan \\
\hline $\begin{array}{l}\text { RUANG } \\
\text { PERAWATAN } \\
\text { KAKI DAN } \\
\text { TANGAN }\end{array}$ & $\begin{array}{l}\text { 1. Pencahayaan } \\
\text { bagus } \\
\text { 2. View langsung } \\
\text { menghadap ke } \\
\text { taman luar }\end{array}$ & $\begin{array}{l}\text { Cahaya ma- } \\
\text { tahari terlalu } \\
\text { banyak masuk } \\
\text { karena jendela } \\
\text { kaca besar }\end{array}$ \\
\hline
\end{tabular}

Gambar diatas merupakan tampilan perencanaan ruang perawatan kaki dan tangan. Jika dilihat pada gambar, ruangan tersebut berbentuk persegi panjang dengan salah satu sisi dinding menggunakan kaca oneway atau kaca satu arah dengan maksud orang-orang yang berada didalam bisa melihat suasana luar dengan view taman luar dan kolam renang dan orangorang yang berada diluar ruangan tidak bisa melihat ke dalam supaya torang yang didalam tidak merasa terganggu. Dengan demikian suasana taman juga bisa dinikmati oleh para pengunjung. dalam satu ruangan perawatan kaki dan tangan ini terdapat tiga sofa untuk melakukan perawatan, meskipun satu ruangan menggunakan lebih dari satu sofa privasi pengunjung asih tetap terjaga karena antara sofa satu dengan lainnya terdapat tirai pemisah.

\section{d. Ruang perawatan rambut}

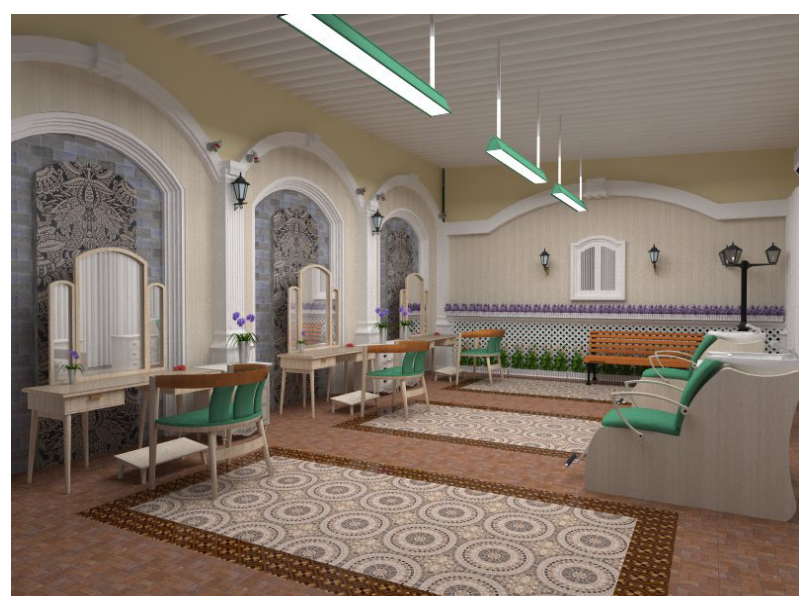

Gambar 14

Sumber : Galang, 15 November 2014

\begin{tabular}{|l|ll|l|}
\hline \multicolumn{1}{|c|}{$\begin{array}{c}\text { Nama } \\
\text { Ruang }\end{array}$} & Kelebihan & Kekurangan \\
\hline $\begin{array}{l}\text { RUANG } \\
\text { PERAWATAN } \\
\text { RAMBUT }\end{array}$ & 1. & $\begin{array}{l}\text { Ruangan } \\
\text { luas }\end{array}$ & $\begin{array}{l}\text { Pembersihan } \\
\text { pada dinding } \\
\text { harus teratutr }\end{array}$ \\
& 2. & $\begin{array}{l}\text { Sirkulasi } \\
\text { udara bagus }\end{array}$ & \\
\hline
\end{tabular}

Ruang perawatan rambut atau sering juga disebut dengan hair spa room ini memiliki 3 set meja rias dan 2 kursi cuci rambut (creambath) untuk mendukung aktivitas perawatan. Ruangan yang memliki panjang 8 meter dengan lebar 6 meter ini dibagi menjadi tiga tanpa dinding pembatas. Ruang ini berkapasitas 6 orang diantanranya 3 terapis dan 3 pasien.

Jika dilihat dari nama ruang dan pelaku yang ada didalamnya maka karakteristik kegiatannya meliputi kegiatan berajalan, melakukan perawatan sampai dengan selesai dan keluar. Ruangan ini tidak begitu private karena perawatan yang dilakukan perawatan pada rambut. Akan tetapi desain ruangan pada ruang perawatan ini sangatlah penting untuk mendukung aktivitas di dalamnya. 


\section{e. Area senam dan yoga}

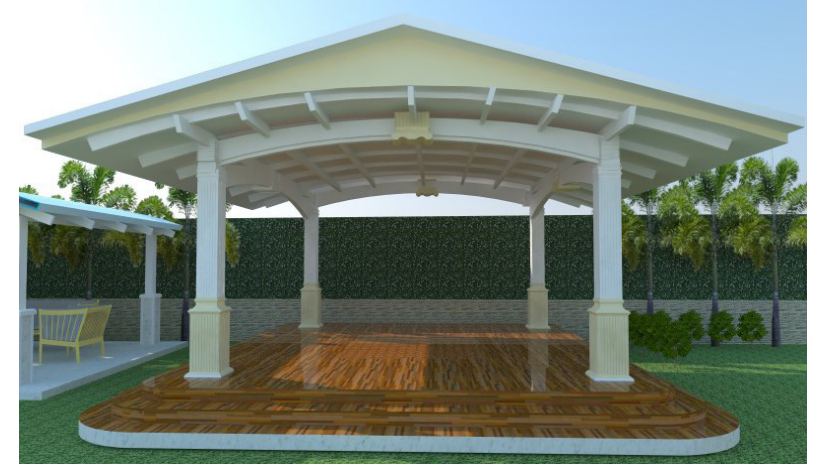

Gambar 15

Sumber : Galang, 15 November 2014

\begin{tabular}{|l|l|l|}
\hline Nama Ruang & \multicolumn{1}{|c|}{ Kelebihan } & \multicolumn{1}{c|}{ Kekurangan } \\
\hline $\begin{array}{l}\text { AREA } \\
\text { SENAM } \\
\text { DAN YOGA }\end{array}$ & $\begin{array}{l}\text { 1. Udara dan caha- } \\
\text { ya alami } \\
\text { 2. Pandangan luas } \\
\text { ke taman }\end{array}$ & $\begin{array}{l}\text { Udara dan ca- } \\
\text { haya tidak bisa } \\
\text { diatur }\end{array}$ \\
\hline
\end{tabular}

Area senam dan yoga mempunyai empat tiang untuk menyangga rangkaian atap. Area senam ini mengadopsi bentuk pendapa pada lantai dan struktur tiang. Karena mengadopsi pendapa area ini tidak memiliki dinding untuk mengelilinginya. Aktivitas senam dan yoga diletakkan di area ini dikarenakan supaya udara alami bisa langsung dirasakan oleh para pelaku senam dan yoga tersebut.

\section{f. Ruang bilas}

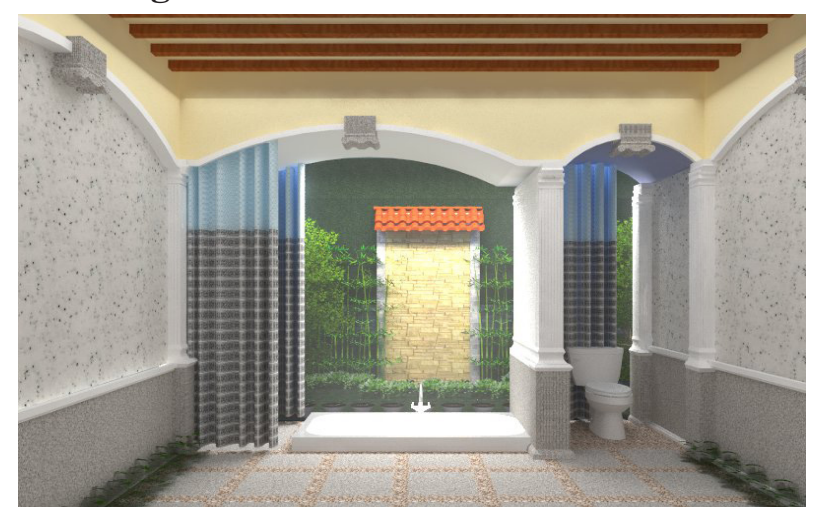

\section{Gambar 16}

Sumber : Galang, 15 November 2014
Ruang bilas dan berendam ini didesain guna memenuhi kebutuhan para pasien yang sudah dirawat dan ingin membilas tubuhnya dengan air bersih. Ruang bilas sudah menjadi syarat utama didalam area spa. Ruangan ini hanya untuk kapasistas 1orang artinya ruangan ini sangat privat. Aktivitas yang dilakukan oleh para pelaku ialah mulai dari berjalan, berendam di bathub, berbilas di shower, sampai selesai.

Karena merupakan syarat utama didalam area spa maka desain ruang bilas ini sangatlah diperhatikan dari segi estetika, kenyamanan hingga keamanannnya. Dari dalam ruangan bilas ini pasien bisa menikmati hijaunya taman yang berada dibelakang ruangan yang dibatasi dinding kaca agar suasana santai lebih terasa.

\section{KESIMPULAN}

Perencanaan Interior Griya spa dan kesehatan untuk ibu hamil di Blitar merupakan sarana umum yang ditujukan kepada para Ibu yang sedang mengandung sebagai tempat untuk memanjakan tubuh melalui metode perawatan tubuh dan kesehatan. Perencanaan ini diharapkan bisa memenuhi aktifitas pengelola dan pengunjung dengan secara baik, aman dan nyaman. Perencanaan ini mempertimbangkan akan aktifitas dan kebutuhan ruang, pemilihan lokasi dan gaya hidup masyarakat.

Pada perencanaan ini diharapkan mampu memberikan dampak positif bagi semua pihak, baik pengelola maupun pengunjung. Pemilihan lokasi di Blitar ini karena saya sendiri berasal dari kota Blitar, selain itu gaya hidup masyarakat Blitar yang semakin berkembang menjadi salah satu pertimbangan perencanaan ini di tempatkan di Blitar.

Perencanaan ini mengambil tema taman sebagai nyawa suasana interior. Tema taman dipilih karena sasaran desain yang utama 
adalah para ibu-ibu yang sedang mengandung. Diharapkan tema taman bisa memberikan dampak positif bagi psikologi ibu hamil. Tema taman ini didukung dengan gaya mediteranian dimana gaya tersebut menghadirkan aksenaksen lengkung, list profil, jendela-jendela besar, penggunan material alam. Unsur-unsur tersebut sangat mendukung tema taman.

Perencanaan Griya spa dan kesehatan untuk ibu hamil di Blitar ini memiliki fasilitas diantaranya : lobby, ruang perawatan tubuh, ruang perawatan tangan dan kaki, ruang perawatan rambut, area kesehatan meliputi : senam; yoga; dan renang, ruang bilas, area kantor, ruang terapis, ruang rapat, ruang dapur, mushola, ruang perlengkapan dan ruang perawatan. Tentunya ruang-ruang tersebut sesuai dengan standarisasi yang ditetapkan oleh Dinas pariwisata provinsi Daerah Istimewa Yogyakarta bekerjasama dengan Asosiasi Spa Indonesia (ASPI).

\section{DAFTAR PUSTAKA}

\section{Buku}

Tri S, Edi; Sunarmi; Ahmad Fajar A. 2012. Buku ajar mata kuliah desain interior public. Surakarta: UNS Press.

Sunarmi. 2008. Buku pegangan kuliah metodologi desain program studi desain interior, metedologi desain, Surakarta: Program Studi Desain Interior, Institut Seni Indonesia Surakarta.

Marlina, Endy. 2008. Panduan perancangan bangunan komersial. Yogyakarta: Andi.

Suptandar, Pamudji. 1999. Desain interior pengantar merencana interior untuk mahasiswa desain dan arsitektur. Jakarta: Penerbit Djambatan
Setiawan, Suzana. 2009. Rumah eko spa untuk ibu hamil dan pasca melahirkan di surabaya. Universitas Kristen Petra.

Anugrah, Adi. 2004. Merawat dan memelihara taman. Bekasi: PT Adi tata usaha.

Sunarmi. 2007. Interior public. Surakarta: Program Studi Desain Interior Jurusan Seni Rupa, Institut Seni Indonesia Surakarta.

Sunarmi. 2005. Modul mata kuliah desain interior II. Surakarta: STSI.

D.K. Ching, Francis. 2001. Edisi kedua desain interior dengan ilustrasi. Jakarta: PT Indeks.

\section{Narasumber}

Wawancara dengan Ibu Retno selaku terapis Spa dan Kecantikan Griya Putri Kedhaton di Yogyakarta.

Wawancara dengan Dinas Pariwisata Provinsi Yogyakarta selaku pembuat standarisasi tempat SPA seluruh Indonesia.

Wawancara dengan Ibu Naning selaku Ibu hamil.

\section{Internet}

www.edupaint.com

www.kamusbahasaindonesia.org

www.ibuhamil.com 